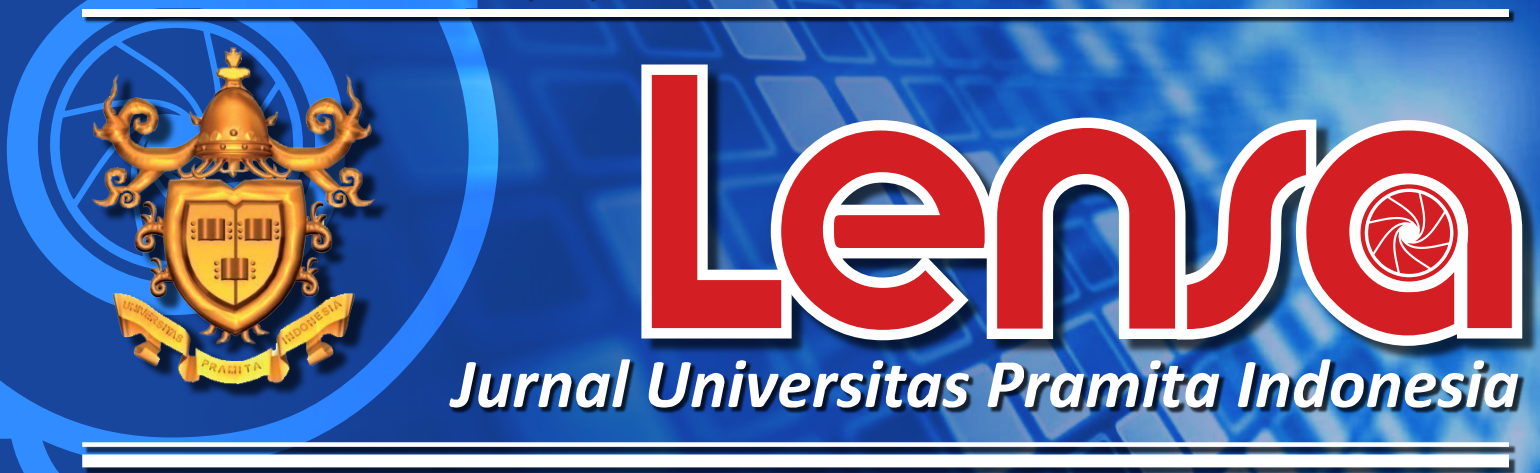

1. Implementasi Rencana Strategis (Renstra) Dalam Pelaksanaan Pembangunan Desa (Studi Kasus Penerapan Rencana Strategis Kabupaten Sumedang Di Desa Tanjung Mekar Kecamatan Tanjung Kerta)

Dr. Drs. Hariawan Bihamding, MT

2. Kewirausahaan Sosial Badan Usaha Milik Desa "Tirta Mandiri" Desa Ponggok

Hari Harjanto Setiawan

3. Peran Kepala Desa Dalam Pembangunan Infrastruktur Fisik Di Desa Sukadiri Kecamatan Sukadiri Tangerang Asri Setiani, S.IKom., M.Si dan Intan Rachmina Koho, S.I.P., M.Si

4. Model Ideal Kepemimpinan Pemerintahan Berbasis Kearifan Lokal Budaya Sunda Bagi Masyarakat Purwakarta (Studi Kepemimpinan Bupati Purwakarta Periode 2008 -2018)

Ednawan Prihana, Ngadisah, Muhadam Labolo, Kusworo

5. Manajemen Kinerja Forum Kerukunan Umat Beragama (Fkub) Tangsel Dalam Menyelesaikan Konflik Dan Mewujudkan Kerukunan Antar Umat Beragama Di Kota Tangerang Selatan Slamet Suwanto

6. Pemanfaatan Media Sosial Sebagai Sarana Komunikasi Korporat Pada Pusat Perbelanjaan Tangcity Mall Intan Amallia Ratna, S.Ikom., M.Si 


\section{Lensa Jurnal Universitas Pramita Indonesia}

Volume 3, No. 49 Maret-September 2020

Lensa, Jurnal Universitas Pramita Indonesia, diterbitkan 2 (dua) kali setahun pada bulan Maret dan September oleh Lembaga Penelitian dan Pengabdian Masyarakat Universitas Pramita Indonesia.

Dalam setiap terbitnya Lensa mencakup tiga disiplin ilmu sesuai dengan Fakultas yang tersedia di Universitas Pramita Indonesia, yaitu: IImu Sosial dan IImu Politik, Ekonomi dan Teknik.

\section{Pelindung/Penasihat}

Drs. H. Hasdanil, M.Si Rektor UNPRI

Pimpinan Redaksi Ednawan Prihana, S. IP, M.Si

Dewan Redaksi Rastanto Hadinegoro, ST, MT Slamet Suwanto, M.Si

Penyunting Intan Rachmina K, S.IP. M.Si Yoyok Cahyono, SE, MM Khaerul Fahmi, ST, MM, MT

Sekretaris Redaksi Rahmawaty, M.Hum

\section{Alamat Redaksi}

Griya Pramita Lt. 4 Jl. Kampus Pramita, Binong, Curug Tangerang 15810 - Banten Telp (021) 5984470 \& Fax (021) 5984467

Email: jurnal_lensa1@gmail.com

\section{DAFTAR ISI}

1 Implementasi Rencana Strategis (Renstra) Dalam Pelaksanaan Pembangunan Desa (Studi Kasus Penerapan Rencana Strategis Kabupaten Sumedang Di Desa Tanjung Mekar Kecamatan Tanjung Kerta), Dr. Drs. Hariawan Bihamding, MT 1-18

2 Kewirausahaan Sosial Badan Usaha Milik Desa "Tirta Mandiri" Desa Ponggok, Hari Harjanto Setiawan

3 Peran Kepala Desa Dalam Pembangunan Infrastruktur Fisik Di Desa Sukadiri Kecamatan Sukadiri Tangerang, Asri Setiani, S.IKom., M.Si dan Intan Rachmina Koho, S.I.P., M.Si

4

Model Ideal Kepemimpinan Pemerintahan Berbasis Kearifan Lokal Budaya Sunda Bagi Masyarakat Purwakarta (Studi Kepemimpinan Bupati Purwakarta Periode 2008 -2018), Ednawan Prihana, Ngadisah, Muhadam Labolo, Kusworo 51-62

5 Manajemen Kinerja Forum Kerukunan Umat Beragama (FKUB) Tangsel Dalam Menyelesaikan Konflik Dan Mewujudkan Kerukunan Antar Umat Beragama Di Kota Tangerang Selatan, Slamet Suwanto 63-83

6 Pemanfaatan Media Sosial Sebagai Sarana Komunikasi Korporat Pada Pusat Perbelanjaan Tangcity Mall, Intan Amallia Ratna, S.Ikom., M.Si

84-91 


\title{
MODEL IDEAL KEPEMIMPINAN PEMERINTAHAN BERBASIS KEARIFAN LOKAL BUDAYA SUNDA BAGI MASYARAKAT PURWAKARTA
}

(Studi Kepemimpinan Bupati Purwakarta Periode 2008 -2018)

Oleh: Ednawan Prihana, Ngadisah, Muhadam Labolo, Kusworo

\begin{abstract}
Abstrak
Tulisan ini berlatar belakang adanya fenomena menarik dan unik di Kota Purwakarta tentang model kepemimpinan pemerintahan yang berbasis kearifan lokal budaya Sunda. Kota Purwakarta tidak hanya melakukan pembangunan fisik di infrastruktur, Namun telah pula membangun mindset masyarakat Purwakarta untuk lebih mencintai kearifan lokal dan melestarikan budaya Sunda dengan mengedepankan nilai-nilai Sunda. Nilai-nilai leluhur budaya Sunda dijadikan spirit membangun kota Purwakarta. Penelitian ini menggunakan desain penelitian diskriptif dengan pendekatan kualitatif, Teknik pengumpulan data dengan metode studi dokumentasi, wawancara dan observasi. Informan yang dipilih merupakan orang yang benar-benar mengetahui permasalahan yang akan diteliti dengan metode triangulasi.
\end{abstract}

Kesimpulan dari hasil penelitian ini sebagai berikut: (1).Model kepemimpinan "Harmoni Gaya Sunda" merupakan formula yang ideal sebagai alternatif dari model kepemimpinan eksisting. Model ini menekankan pada keselarasan dan keseimbangan antara unsur Gaya (Agama dan Budaya) Sunda dimana posisi Agama dan Budaya Sunda seimbang, Posisi idealnya di titik equilibirium mencari keseimbangan. (2) Faktor-faktor pendukung kesuksesan: kultur masyarakat, Bupati sendiri dalam kepemimpinannya mencintai budaya Sunda dan menguasai konsep nilai-nilai kepemimpinan Sunda. Sedangkan Faktor-faktor Penghambatnya yakni: Perbedaan pola pikir, komunikasi yang kurang efektif dan rendahnya kualitas Sumber Daya Manusia (SDM)

Saran yang dapat diberikan: (1) Model Kepemimpinan "Harmoni Gaya Sunda" merupakan model ideal untuk masyarakat Purwakarta. Dengan penerapan model ini dinamika yang timbul di masyarakat dapat diminimalisir. Diperlukan telaah dan pengkajian lebih mendalam melalui Focus Group Discussion (FGD) oleh Pemkab Kabupaten Purwakarta untuk penerapan model ini agar efektivitasnya dapat lebih maksimal. (2) Faktor-faktor pendukung kesuksesan Kepemimpinan Bupati Purwakarta: kultur masyarakat, Bupati sendiri dalam kepemimpinannya mencintai budaya Sunda dan menguasai konsep nilai-nilai kepemimpinan Sunda. Faktor tersebut perlu dipertahankan. Faktor-faktor Penghambat yakni: Perbedaan pola pikir, komunikasi yang kurang efektif dan rendahnya kualitas Sumber Daya Manusia (SDM) merupakan area tantangan yang perlu diperbaiki dan ditingkatkan menjadi efektif.

Kata kunci: Kepemimpinan, Kepemimpinan Pemerintahan, Kearifan lokal, Budaya Sunda 


\begin{abstract}
This research is based on a unique and interesting phenomenon about government leadership which stands on Sundanese's local wisdom in Purwakarta. Purwakarta builds not only it's infrastructure, but also it's people's mindset to love more and to preserve the Sundane's Local Wisdom by putting forward the it's value. Sundanese ancestry value has become the spirit of Purwakarta development. This research is a descriptive research with a qualitative methodology. The technics of data mining for this study are a documentation study method, interview, and observation. The informant for this research is consisted of selected experts as a way of implementing triangulation methodology.

In sum, (1). The leadership model "Sundanese Style Harmony" is an ideal formula as an alternative to the existing leadership model. This model emphasizes harmony and balance between elements of Sundanese Style (Religion and Culture) where the position of Sundanese Religion and Culture is balanced. The ideal position is at the equilibirium point of finding balance. (2) Success supporting factors: community culture, the Regent himself in his leadership loves Sundanese culture and masters the concept of Sundanese leadership values. While the inhibiting factors are: Differences in mindset, ineffective communication and low quality of Human Resources (HR)

Suggestions that can be given: (1) Leadership Model "Sundanese Style Harmony" is an ideal model for the people of Purwakarta. By applying this model the dynamics that arise in the community can be minimized. A deeper study and assessment is needed through a Focus Group Discussion (FGD) by the District Government of Purwakarta for the application of this model so that its effectiveness can be maximized. (2) Supporting factors for the success of Purwakarta Regent Leadership: community culture, the Regent himself in his leadership loves Sundanese culture and masters the concept of Sundanese leadership values. These factors need to be maintained. Inhibiting factors namely: Differences in mindset, ineffective communication and poor quality of Human Resources $(H R)$ are areas of challenge that need to be fixed and improved to be effective.
\end{abstract}

Keyword: Leadership, Government Leadership, Local Wisdom, Sundanese Culture 


\section{PENDAHULUAN}

Kota Purwakarta memperlihatkan perkembangan yang menarik, paling tidak sejak sepuluh tahun terakhir. Purwakarta melakukan sesuatu yang tak lazim dalam konteks kepemimpinan, birokrasi dan kebijakan pembangunan. Bupati Kabupaten Purwakarta membangun daerahnya dengan menggunakan pendekatan kepemimpinan pemerintahan yang berbeda dengan daerah lainnya. Hal ini merupakan sebuah terobosan yang baru dan apa yang dilakukan di Purwakarta ini belum banyak dilakukan oleh Kepala Daerah lainnya.

Purwakarta tidak hanya melakukan pembangunan di infrastruktur, namun juga menjalankan nilai-nilai daerah setempat yakni nilai-nilai budaya Sunda yang diterapkan di setiap aspek pemerintahan di Kabupaten Purwakarta. Bupati Purwakarta periode tahun 2008-2018 mencoba membangun mind set warga Purwakarta untuk lebih mencintai kearifan lokal, melestarikan budaya Sunda dengan melakukan pembangunan yang mengedepankan nilai-nilai budaya Sunda . Bupati Purwakarta periode 2008-2018 ini telah secara konsisten membangun daerahnya dengan nilai-nilai budaya Sunda di alam demokrasi Indonesia. Nilai-nilai leluhur budaya Sunda dijadikan spirit membangun Kota Purwakarta dan sebagai spirit fundamental masyarakat. Banyak kebijakan yang dibuat Bupati Purwakarta periode tahun 2008-2018 yang dikeluarkan berangkat dari ranah khas budaya Sunda. Penataan Kota Purwakarta telah banyak membangun patung pewayangan, tokoh sunda, tokoh bangsa seperti patung Soekarno \& Hatta, Gus Dur dan lain-lain. Adanya pembangunan taman dan situ, seperti air mancur terbesar di
Indonesia, bercorak-berirama di situ Buleud Taman Sri Baduga, dan banyak taman lainnya di Kota Purwakarta menjadikan Kota Purwakarta sebagai sebuah kota yang bersih, rapi dan menarik

Kepemimpinan Pemerintahan Bupati Purwakarta periode tahun 2008-2018 yang berbasis kearifan lokal budaya sunda ini berbuah meraih berbagai keberhasilan, salah satunya adalah penghargaan dari Komisi Pemberantasan Korupsi (KPK) yang telah menganugerahi Kabupaten Purwakarta sebagai daerah terbaik dalam pengelolaan LHKPN 2016 . Dedi Mulyadi juga diundang Perserikatan Bangsa Bangsa (PBB) pada bulan Juli 2016 bertema Kepemimpinan Moral Visi Berbasis Kebudayaan Sunda . The Sukarno Center pada bulan Juli 2016 juga telah menganugerahi Bupati Dedi Mulyadi sebagai Pemimpin Teladan Demokrasi . Dedi Mulyadi juga meraih penghargaan sebagai Kepala Daerah Inovatif pada tahun 2015 dan 2016 dari MNC Grup . Dengan berbagai keberhasilan yang telah dicapai tersebut, Pemerintah Kabupaten Purwakarta telah mendapatkan berbagai penghargaan baik di lingkup internasional, nasional maupun provinsi.

Tetapi dalam kepemimpinan pemerintahan Bupati Purwakarta tersebut tak lepas pula dari berbagai dinamika dan polemik yang timbul di masyarakat. Penataan kota di Purwakarta sekarang ini memang sangat berubah, dikarenakan Bupati Purwakarta ingin mengembalikan kebudayaan leluhur yang hampir hilang karena perubahan zaman. Tetapi muncul permasalahan baru di sebagian kalangan masyarakat karena setelah dilihat dan diamati perubahan yang terjadi di kota Purwakarta lebih mirip kebudayaan Bali. contohnya terdapat 
patung-patung tokoh pewayangan hampir di setiap perempatan jalan, tempat-tempat wisata dan taman kota, pendirian gapura pada setiap gang, bentuk pagar kantor pemerintahan dan fasilitas umum, pohonpohon di kota dan dilingkungan kantor pemerintahan daerah diikat kain bercorak kotak bergaris kuning, apakah kebudayaan Sunda dan Bali sama? .

Bupati Purwakarta Periode tahun 20082018 telah mengeluarkan kebijakankebijakan dan menimbulkan dinamika di kepemimpinannya, salah satu contoh adalah kebijakan ideologis yang dianggap sebagian masyarakat bertentangan dengan kebiasaan rutin di masyarakat, tujuannya agar kebudayaan Sunda tetap hidup dikampungnya sendiri. Selama ini tidak ada rumusan simbolistik tentang karakter wilayah yang mencerminkan kebudayaan. Kebijakan ideologis tersebut diwujudkan dalam kebijakan pembangunan daerah dengan nilai-nilai Sunda dalam kepemimpinannya. Nilai-nilai Sunda tersebut dituangkan berupa slogan 'Spirit Budaya”.

Kebijakan khas yang menimbulkan kontroversi lainnya seperti membangun patung-patung tokoh Sunda di setiap sudut Kabupaten Purwakarta, penerapan kain hitam putih pada setiap bangunan di Kabupaten Purwakarta, sebagian masyarakat menganggap penggunaan nilai-nilai kearifan lokal budaya Sunda ini telah keluar dari ajaran agama Islam dan masyarakat menganggap adanya hindunisasi di Kabupaten Purwakarta. Bahkan sebagian masyarakat menilai pembangunan yang dilaksanakan terkesan dipaksakan dan tidak sesuai dengan skala prioritas kebutuhan masyarakat yang akhirnya berakibat adanya penolakan dari masyarakat terkait kepemimpinan dan kebijakan Bupati Purwakarta periode tahun 2008- 2018.

Kebijakan khas lainnya yang menimbulkan pro dan kontra adalah Peraturan Bupati Nomor 69 Tahun 2015 tentang Pendidikan Berkarakter. Dikeluarkannya peraturan bupati ini berdampak pada perubahan sistem pendidikan di Kabupaten Purwakarta dan menimbulkan dinamika. Jam masuk sekolah dimana untuk daerah pedesaan masuk pada pukul 06.30 Wib s/d 10.30 Wib sedangkan untuk wilayah perkotaan dimulai pukul 07.00 Wib s/d 15.00 Wib. Selain itu terdapat pula perubahan dalam seragam sekolah sebagaimana diatur dalam peraturan bupati tersebut yang menghilangkan seragam sekolah asli digantikan dengan pakaian pramuka pada hari Senin, pakaian adat Sunda pada hari Selasa dan Rabu, Pakaian batik pada hari Kamis serta busana muslim pada hari Jumat. Lebih lanjut peraturan bupati tersebut mengatur terkait kewajiban membawa makan/minuman kesekolah dan menghilangkan kantin-kantin yang ada di lingkungan sekolah.

Peneliti mencoba membuat model kepemimpinan yang ideal dan efektif bagi masyarakat Purwakarta agar kepemimpinnya dapat meminimalisir dinamika yang timbul di masyarakat dan kepemimpinannya dapat ditrima oleh masyarakat secara lebih luas.

\section{TINJAUAN PUSTAKA}

\section{a. Ilmu Pemerintahan}

Menurut U.Rosenthal "De bestuurswetenchap is de wetenschap die zich uitsluited bezighoudt met de studie van interneen externewerking van de structuren en prosessen". Ilmu 
pemerintahan sebagai ilmu yang secara otonom mempelajari bekerjanya strukturstruktur dan proses-proses pemerintahan yang melibatkan kebijaksanaan dan keputusan yang bersifat mengikat untuk dan atas nama kehidupan bersama.

Menurut Brasz ilmu pemerintahan yaitu ilmu yang mempelajari cara bagaimana lembaga-lembaga pemerintahan umum disusun dan difungsikan terhadap warga negara baik secara internal maupun secara eksternal.

Menurut Syafiie Ilmu pemerintahan adalah ilmu yang mempelajari bagaimana melaksanakan pengurusan (eksekutif), pengaturan ((legislatif), kepemimpinan dan koordinasi pemerintahan ( baik pusat dengan daerah, maupun rakyat dengan pemerintahnya) dalam berbagai peristiwa dan gejala pemerintahan, secara baik dan benar.Pemerintah tidaklah diadakan untuk melayani diri sendiri, tetapi untuk melayani masyarakat, menciptakan kondisi yang memungkinkan setiap anggota mengembangkan kemampuan dan kreatifitasnya demi mencapai kemajuan bersama

Ndraha mengatakan bahwa pemerintah memegang pertanggungjawaban atas kepentingan rakyat. Lebih lanjut Ndraha juga mengatakan bahwa pemerintah adalah semua beban yang memproduksi, mendistribusikan, atau menjual alat pemenuhan kebutuhan masyarakat berbentuk jasa publik dan layanan civil. Sejalan dengan itu, Kaufman dalam Thoha, menyebutkan bahwa Tugas pemerintahan adalah untuk melayani dan mengatur masyarakat. Kemudian dijelaskan lebih lanjut bahwa tugas pelayanan lebih menekankan upaya mendahulukan kepentingan umum, mempermudah urusan publik dan memberikan kepuasan kepada publik, sedangkan tugas mengatur lebih menekankan kekuasaan power yang melekat pada posisi jabatan birokrasi.

\section{b. Kepemimpinan Pemerintahan}

Kepemimpinan Pemerintahan menurut Taliziduhu Ndraha adalah terapan teori kepemimpinan didalam bidang pemerintahan. Sudah barang tentu,terapan ini diwarnai oleh sifat-sifat khas bidang pemerintahan itu sendiri.Oleh karena itu dapat pula dikatakan kepemimpinan pemerintahan menunjukkan daerah perbatasan antara ( yang menghubungkan) gejala kepemimpinan dengan gejala pemerintahan. Lebih lanjut Ndraha mengatakan bahwa konsep kepemimpinan pemerintahan terdiri dari dua (sub) konsep yang hubungannya satu dengan yang lain, tegang, yaitu konsep kepemimpinan bersistem nilai sosial dan konsep pemerintahan yang mengandung sistem nilai formal. Setiap saat, seorang pemimpin formal atau kepala yang berkepemimpinan dihadapkan pada berbagai situasi dan perubahan yang cepat. Ia harus memilih peran, sebagai kepala atau sebagai pemimpin. Dilihat dari sudut itu, pada saat seeorang melakukan suatu peran, ia harus mempertimbangkan peran lainnya. Peran apa mendukung peran apa, peran mana dapat menghambat peran mana, peran apa conflicting dengan peran apa dan seterusnya

\section{c. Kearifan Lokal}

Kearifan lokal (local genius) menurut Poespowardojo adalah kecerdasan manusia yang dimiliki oleh sekelompok (etnis) manusia yang diperoleh melalui pengalaman hidupnya serta terwujud dalam ciri-ciri budaya yang dimilikinya. Dapat diartikan bahwa seorang anggota masyarakat yang berbudaya menjadi 
cerdas berkat pengalaman hidup yang dihayatinya. Kearifan dalam budaya merupakan bentuk kecerdasan yang dihasilkan oleh masyarakat pemilik kebudayaan yang bersangkutan.

Kearifan lokal adalah merupakan kebenaran yang telah mentradisi atau ajeg dalam suatu daerah. Kearifan lokal merupakan perpaduan antara nilai-nilai suci firman tuhan dan berbagai nilai yang ada. Kearifan lokal terbentuk sebagai keunggulan budaya masyarakat setempat maupun kondisi geografis dalam arti luas. Kearifan lokal merupakan produk budaya masa lalu yang patut secara terus-menerus dijadikan pegangan hidup. Kearifan lokal secara substansial merupakan norma yang berlaku dalam suatu masyarakat yang diyakini kebenarannya dan menjadi acuan dalam bertindak dan berperilaku seharihari. Oleh karena itu, kearifan lokal merupakan entitas yang sangat menentukan harkat dan martabat manusia dalam komunitasnya

\section{d. Budaya Sunda}

Budaya Sunda merupakan salah satu kekayaan budaya yang dimiliki oleh Negeri Indonesia. Sebagai salah satu akar budaya nasional, budaya Sunda sebenarnya lahir karena tradisi yang dianut dan dikembangkan oleh suku Sunda yang kebanyakan tinggal di provinsi Jawa Barat. Oleh karena itu, banyak sekali yang mengidentikkan budaya Sunda dengan budaya Jawa Barat.

Karakteristik kuat dari budaya Sunda terletak pada sopan santun dan keramah tamahan suku Sunda. Maka tak heran, masyarakat Jawa Barat terkenal murah senyum, ramah, lemah lembut, sopan dan menghargai orang yang lebih tua. Kesopanan dan kelemah-lembutan Urang
Sunda bisa dilihat dari bahasa Sunda dan cara mengucapkan bahasa tersebut, selain tersusun dengan sopan, cara mengucapkannya juga terbilang lembut. Sehingga membuat orang yang mendengarnya tidak berani untuk marah. Di bahasa Sunda, juga terdapat perbedaan penggunaan bahasa Sunda untuk usia-usia tertentu. Bagaimana caranya berbicara dengan orang sebaya dan orang yang lebih tua atau muda, semuanya ada aturannya.

Cageur, Bageur, Singer dan Pinter juga merupakan salah satu karakteristik budaya Sunda yang sangat terkenal. Karakter ini menunjukkan Urang Sunda yang bersatu mencapai keutamaan dan tujuan hidup. Watak kuat ini tentunya akan sangat baik jika benar-benar dimiliki oleh Urang Sunda. Sebuah tekad yang kuat untuk mencapai tujuan.

Kehidupan religius di Budaya Sunda juga terbilang sangat rukun. Hal ini merupakan karakteristik dari Urang Sunda yang memang memegang teguh toleransi. Budaya Sunda mengajarkan untuk saling menghargai satu sama lain karena mereka percaya bahwa semua agama pada dasarnya mengajarkan untuk rukun dan damai. Meskipun ajaran agama secara khusus memiliki perbedaan dalam hal tasawuf. Ada satu karakteristik unik lainnya dari budaya Sunda yaitu silih asih silih asah silih asuh. Arti dari kalimat tersebut adalah untuk saling mengasihi satu sama lain, lalu mempertajam diri, dan saling melindungi dan tolong menolong.

Lebih jauh, budaya Sunda mengajarkan banyak hal pada masyarakatnya. Termasuk kesopanan, rendah hati, kekompakan, gotong royong, kerja sama, saling menyayangi, dan lain sebagainya. Hal ini bisa dilihat pada bagian budaya Sunda seperti tarian atau saat upacara adat 
tertentu. Upacara adat yang masih dilaksanakan bersama-sama untuk membuktikan budaya Sunda yang lestari sekaligus mengingatkan pada semua orang akan nilai-nilai budaya Sunda

\section{METODE PENELITIAN}

Metode Penelitian ini menggunakan desain penelitian diskriptif dengan pendekatan kualitatif, Teknik pengumpulan data dengan metode studi dokumentasi, wawancara dan observasi. Informan yang dipilih merupakan orang yang benar-benar mengetahui permasalahan yang akan diteliti dengan metode triangulasi.

\section{HASIL DAN PEMBAHASAN}

\section{Model Existing}

Model merupakan suatu pola dan style dalam menggambarkan logika yang dapat diaplikasikan salah satunya terhadap sebuah kebijakan dalam mengambil suatu keputusan. Model kepemimpinan pemerintahan berbasis kearifan lokal budaya Sunda dari bupati Purwakarta periode tahun 2008-2018 secara prinsip menjelaskan tentang kepemimpinan dengan menggunakan kepemimpinan kearifan lokal budaya Sunda. Model tersebut dapat digambarkan sebagai berikut:

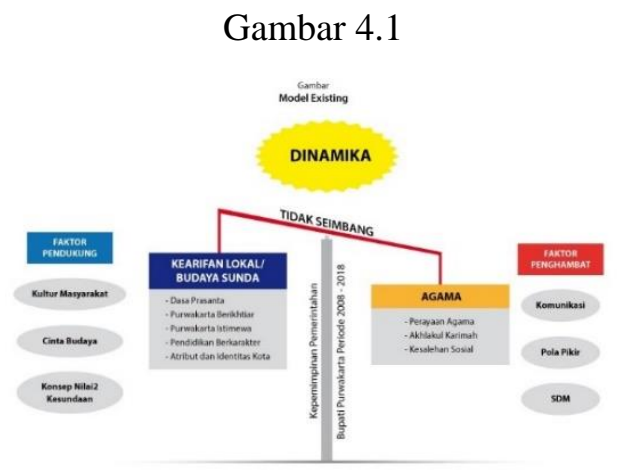

Dari gambar diatas, dapat dijelaskan bahwa dalam kepemimpinan bupati Purwakarta periode tahun 2008-2018 tejadi pro dan kontra di masyarakat dan menimbulkan dinamika, hal ini disebabkan adanya ketidakseimbangan antara porsi faktor budaya dan faktor agama. Faktor Budaya posisinya lebih tinggi dibanding faktor budaya, Sebagian masyarakat menilai bupati lebih mengunggulkan dan mengedepankan budaya dan kearifan lokal dibanding dengan agama. Agama dipandang oelh sebagian masyarakat lebih dikesampingkan, sehingga menimbulkan kecemburuan sosial bagi kalangan yang mengutamakan agama. Keinginan dan kebutuhan dari kelompok agama dirasa kurang diakomodir oleh bupati dan merasa dianak-duakan sehingga menimbulkan persepsi dan pola pikir yang negatif tehadap kebijakan bupati, terutama yang berkaitan dengan pembangunan patungpatung di kota Purwakarta yang dianggap melanggar syariat agama Islam sehingga menimbulkan gejolak dan dinamika di masyarakat.

Di sisi lain, kelompok penentang mengatakan bahwa bupati lebih fokus dan mengutamakan kebijakan-kebijakan yang berkaitan dengan kearifan lokal dan budaya Sunda. Banyak sekali kebijakankebijakan kearifan lokal budaya Sunda yang sudah diimplementasikan di masyarakat seperti Purwakarta Berkarakter dengan Spirit Budaya nya. Pendidikan Berkarakter, Purwakarta Istimewa dan pembangunan identitas dan atribut kota.

Komunikasi yang dilakukan oleh bupati kepada elemen masyarakat dirasa kurang dan belum maksimal, terutama kepada kelompok penentang kebijakannya. Koordinasi dalam implementasi kebijakan-kebijakan yang cukup sensitif di 
terapkan masyarakat kurang melibatkan kelompok-kelompok tersebut, sehingga mereka merasa tidak diajak bicara dan ditinggalkan, padahal mereka juga termasuk bagian dari elemen masyarakat yang ada di Purwakarta.

\section{Rekonstruksi Model Existing}

Dari model existing dan berdasarkan data dan fakta empirik dilapangan peneliti mencoba merekonstruksi model eksisting kepemimpinan pemerintahan berbasis kearifan lokal budaya Sunda agar meminimalisir terjadinya dinamika dan terjadinya pro-kontra di masyarakat dengan menawarkan model kepemimpinan baru dengan konsep formula keseimbangan atau keselarasan dan harmonisasi antara unsur Agama dan Budaya .

Model kepemimpinan "Harmoni Gaya Sunda“ merupakan singkatan dari harmoni antara aGAma dan budaYA Sunda. Model ini muncul sebagai alternatif untuk menjawab fenomena model kepemimpinan pemerintahan berbasis kearifan lokal budaya Sunda yang ada dan masih memperlihatkan timbulnya dinamika. Model ini dapat dianggap sebagai formula alternatif menjawab permasalahan dinamika yang timbul di masyarakat Purwakarta.

Konsep model kepemimpinan "Harmoni Gaya Sunda " menekankan pada adanya keseimbangan, keselarasan atau harmoni antara dua unsur faktor penting dalam kepemimpinan di masyarakat Purwakarta, yakni agama dan budaya sunda. Model ini mengadaptasi dua kebijakan untuk disatukan, dikemas program-program antara agama dan budaya. membuat program yang kedua-duanya terakomodir. Sehingga adanya keseimbangan dianntara keduanya ( agama dan budaya) sehingga akan lebih luas diterima oleh masyarakat dan lebih luas periodesasinya. Purwakarta label agamanya masih kuat, sedangkan budaya juga terus berkembang dan berubah mengikuti perubahan jaman. Antara kebudayaan dan agama derajat posisinya setara, tidak ada yang di anakemaskan, karena keduanya penting sehingga ada keseimbangan yang satu tidak lebih tinggi atau lebih rendah.

Model Kepemimpinan Harmoni Gaya Sunda dapat divisualisasikan dalam gambar berikut:

\section{Gambar 4.3}

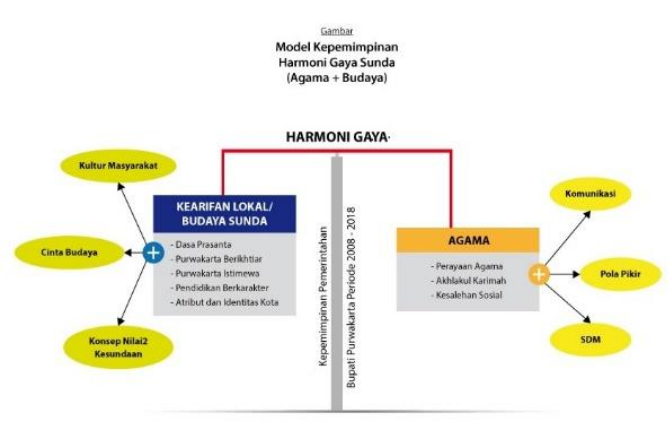

Dalam gambar tersebut, Unsur Kearifan lokal budaya Sunda terdiri dari program Purwakarta berkarakter, Purwakarta Istimewa, Pendidikan Berkarakter dan Pembangunan Atribut \& Identitas Kota serta Kepemimpinan Dasa Prasanta, sedangkan di unsur Agama, Perlu lebih ditingkatkan program-program seperti perayaan keagamaan, kesalehan sosial yang semuanya bermuara pada kepemimpinan yang akhlakul kharimah. Istilah akhlak berasal dari bahasa arab yang berarti budi pekerti, perangai, tingkah laku atau tabiat, serta kebiasaan. Sedangkan karimah adalah artinya mulia, terpuji, baik. Maka yang dimaksud dengan kepemimpinan akhlaqul karimah ialah 
pemimpin yang memiliki budi pekerti atau sebuah perangai yang mulia. Sebuah akhlak memiliki tujuan agar setiap pemimpin bertingkah laku atau bertabiat sesuai dengan adat istiadatnya yang baik dan sesuai dengan ajaran agama Islam.

Disebelah kiri, elemen penting faktor pendukung adalah Kultur Masyarakat dan pemimpin yang cinta budaya Sunda serta menguasai konsep nilai-nilai kesundaaan. Elemen penting tersebut tetap perlu dipertahankan di model kepemimpinan "Harmoni Gaya Sunda".

Selain memperlihatkan unsur kesimbangan antara Agama dan Budaya, Disisi sebelah kanan, elemen penting yang perlu diperhatikan adalah Faktor Penghambat nya yakni: komunikasi, pola pikir dan peningkatan kualitas SDM. Dalam model kepemimpinan Harmoni Gaya Sunda ini faktor penghambat merupakan area tantangan perbaikan agar supaya faktor penghambat dapat berubah menjadi faktor pendukung.

\section{Komunikasi}

Komunikasi merupakan salah satu elemen penghambat dalam kepemimpinan pemerintahan bupati Purwakarta periode tahun 2008-2018, adanya gap atau hambatan komunikasi yang terjadi antara bupati dengan bawahan.. Bawahan kurang terbuka dan takut berkomunikasi dengan pimpinannya, ini menyebabkan adanya hambatan komunikasi antara bupati dan jajaran di bawahannya sehingga berakibat timbulnya miskomunikasi dan koordinasi. Agar supaya model kepemimpinan ini dapat efektif, maka hambatan gap komunikasi harus dihilangkan.

Di model kepemimpinan eksisting, dalam penerapan kebijakan programprogramnya, bupati lebih cenderung untuk jalan dulu, jika ada masalah baru akan diklarifikasi. Sehingga ini yang kadangkadang menimbulkan polemik di masyarakat, walaupun setelah kebijakan tersebut jalan dan banyak manfaatnya bagi masyarakat maka pada akhirnya masyarakat dapat menerima hal tersebut. Perencannaannya matang di bupati namun didalam pelaksanaannya mungkin koordinasinya yang kurang. Contoh seperti pohon ditutup kain, pembangunan patung, diawal tidak dijelaskan makna, tujuan dan filosofinya..yang penting jalan dulu saja. dan kemudian timbul dinamika, walaupun setelah dklarifikasi akhirnya masyarakat yang kontra bisa menerimanya

Di Ilmu Komunikasi ada yang disebut dengan proses komunikasi. Proses komunikasi adalah bagaimana komunikator menyampaikan pesan kepada komunikannya, sehingga dapat menciptakan suatu persamaan makna antara komunikan dengan komunikatornya. Proses komunikasi ini bertujuan untuk menciptakan komunikasi yang efektif (sesuai dengan tujuan komunikasi pada umumnya).

\section{Pola Pikir}

Mindset (Pola pikir) adalah elemen lain yang menjadi faktor penghambat di model kepemimpinan existing. Mindset adalah cara menilai dan memberikan kesimpulan terhadap sesuatu berdasarkan sudut pandang tertentu. Perbedaan pola pikir seseorang disebabkan oleh bedanya jumlah sudut pandang yang dijadikan dasar, landasan atau alasan. Banyaknya sudut pandang seseorang untuk berpikir dipengaruhi oleh emosi (mentality), pendidikan dan pengalaman. Hal ini yang menjadi tolak ukur tinggi rendahnya kedewasaan seseorang. 
Dalam model kepemimpinan eksisting perbedaan pola pikir dari sebagian kelompok yang kontra dengan kebijakan bupati disebabkan adanya perbedaan persepsi terhadap tujuan kebijakankebijakan yang dikeluarkan oleh bupati, terutama yang berkaitan dengan ideologis dan dianggap menyimpang dari ajaran agama islam. Sekelompok masyarakat beragama yg fanatik, dan melihat kegiatan dan aktivitas yang banyak dilakukan Pak Dedi dianggap menyimpang dari ajaran agama islam padahal hal tersebut menyerap dari budaya sunda. Ada anggapan yang kontra dengan bupati , bahwa bukan Islam tapi sunda wiwitan ini menimbulkan kontra. Dalam Islam membuat patung untuk disembah haram hukumnya, namun untuk seni keindahan hal tersebut dirasa sah saja.. Ini karena masih adanya persepsi yang masih berbeda. Oleh karena itu agar model kepemimpinan Harmoni Gaya Sunda dapat efektif, maka menyamakan pola pikir merupakan area tantangan perbaikan.

\section{Meningkatkan Kualitas SDM}

Meningkatkan kualitas SDM merupakan tantangan area pebaikan di model kepemimpinan eksisting, faktor penghambat rendahnya kualitas SDM merupakan pekerjaan rumah yang perlu ditingkatkan dengan pelattihan-pelatihan dan meningkatkan pendidikan ASN. Rendahnya mutu ASN akan mempengaruhi kinerja dan pelayanan kepada publik. Karena Bupati Purwakarta periode tahun 2008-2018 itu akselerasinya cepat, maka ada sebagian ASN atau tim birokrat dibawahnya yang belum bisa mengimbangi irama kecepatannya, sehingga pasti akan tertinggal. Oleh karena itu di dalam model kepemimpinan Harmoni Gaya Sunda peningkatan kualitas mutu SDM dapat mengefektifkan model kepemimpinan tersebut.

Model kepemimpinan "Harmoni Gaya Sunda" merupakan formula yang ideal sebagai alternatif model kepemimpinan eksisting yang menekankan pada keselarasan dan keseimbangan antara unsur Agama dan Budaya Sunda dimana posisi Agama dan Budaya Sunda seimbang, Posisinya tidak ada yang relatif lebih tinggi maupun lebih rendah. Model kepemimpinan ini akan terjadi harmoni jika unsur Agama dan Budaya Sunda posisinya berimbang. Model kepemimpinan ini akan efektif dengan adanya faktor-faktor pendukung yaitu kultur masyarakat Purwakarta, yang senang dengan kearifan lokalnya Pemimpinnya yang cinta budaya sunda dan menguasai konsep- konsp kesundaan.

Faktor komunikasi , perilaku dan perubahan pola pikir masyarakat serta meningkatkan kompetensi SDM baik di masyarakat Purwakarta maupun jajaran ASN adalah faktor-faktor yang perlu ditingkatkan agar model kepemimpinan ini dapat berjalan dengan efektif dan sukses.

\section{KESIMPULAN}

Berdasarkan hasil dan pembahasan sebelumnya maka dapat disimpulkan sebagai berikut:(1).Model kepemimpinan "Harmoni Gaya Sunda" merupakan formula yang ideal sebagai alternatif dari model kepemimpinan eksisting. Model ini menekankan pada keselarasan dan keseimbangan antara unsur Gaya (Agama dan Budaya) Sunda dimana posisi Agama dan Budaya Sunda seimbang, Posisi idealnya di titik equilibirium mencari keseimbangan. (2) Faktor-faktor pendukung kesuksesan: kultur masyarakat, Bupati sendiri dalam kepemimpinannya 
mencintai budaya Sunda dan menguasai konsep nilai-nilai kepemimpinan Sunda. Sedangkan Faktor-faktor Penghambatnya yakni: Perbedaan pola pikir, komunikasi yang kurang efektif dan rendahnya kualitas Sumber Daya Manusia (SDM)

Saran yang dapat diberikan: (1) Model Kepemimpinan "Harmoni Gaya Sunda" merupakan model ideal untuk masyarakat Purwakarta. Dengan penerapan model ini dinamika yang timbul di masyarakat dapat diminimalisir. Diperlukan telaah dan pengkajian lebih mendalam melalui Focus Group Discussion (FGD) oleh Pemkab Kabupaten Purwakarta untuk penerapan model ini agar efektivitasnya dapat lebih maksimal. (2) Faktor-faktor pendukung kesuksesan Kepemimpinan Bupati Purwakarta : kultur masyarakat, Bupati sendiri dalam kepemimpinannya mencintai budaya Sunda dan menguasai konsep nilai-nilai kepemimpinan Sunda. Faktor tersebut perlu dipertahankan. Faktorfaktor Penghambat yakni: Perbedaan pola pikir, komunikasi yang kurang efektif dan rendahnya kualitas Sumber Daya Manusia (SDM) merupakan area tantangan yang perlu diperbaiki dan ditingkatkan menjadi efektif.

\section{DAFTAR PUSTAKA}

Buku \& Karya Ilmiah:

[1] Adair,

John.1997.Effective leadership masterclass: What every managers can learn from the great leaders. Calcuta: Rupa \& Co Bass,

[2] Bernard M. \& Steidlemeier,1998.. Ethics, character, and authentic transformational leadership.Brimingham, NY: Center for Leadership Studie, University of Brimingham.
[3] Covey, Steven R.1989.The 7 habits of highly of effective people.New York \& Schuster

[4] Djaenuri, Aries. Metodologi Penelitian Pemerintahan, Buku Materi Pokok.

[5] Djaenuri, Aries. Kepemimpinan, Etika dan Kebijakan Pemerintahan, 2015, Ghalia Indonesia

[6] Ekadjati, Edi S..2009. Kebudayaan Sunda, Suatu Pendekatan Sejarah, Jilid 1, Pustaka Jaya

[7] Ekadjati, Edi S. 2009.Kebudayaan Sunda, Zaman Pajajaran, Jilid 2, Pustaka Jaya

[8] Harris, Syamsudin, 2006. Membangun Format Baru Otonomi Daerah Cetakan 1. Jakarta:LIPI Press

[9] Irawan, Prasetya. 2006. Penelitian Kualitatif \& Kuantitatif Untuk IlmuIlmu Sosial. Depok: Universitas Indonesia

[10] John W.Creswell, 2017. Research Design, Pendekatan Metode Kualitatif, Kuantitatif dan Campuran. Pustaka Pelajar, Edisi keempat

[11] Kanter,Rosbeth Moss,1977. Men and women of the corporations.New York: Basic Books

[12] Kartono, Kartini, 2008. Pemimpin \& Kepemimpinan, Raja Grafindo

[13] Kasali, Rhenald 2007. Change. Cetakan kesembilan, April 2014: PT Gramedia Pustaka Utama, Jakarta

[14] Kasupardi, Endang, 2014. Cing Caringcing Pageuh Kancing Set Saringset Pageuh Iket - Buah Pemikiran Kang Dedi Mulyadi, CV Trinanda

[15] Kasupardi, Endang, 2016.Adab Sunda, Bagian Humas dan Protokol Setda Kabupaten Purwakarta 
[16] Mc,Iver, 1985. Jaring-jaring Pemerintahan.Aksara Baru. Jakarta

[17] Masoang \& Tilomi. 2011. Kepemimpinan Berbasis Multiple Intelligence (Sinergi Kecerdasan Intelektual, Emosional dan Spiritual Untuk Meraih Kesuksesan yang Gemilang). Bandung: Alfabeta, CV

[18] Moleong, LexyJ 1989. Metode Penelitian Kualitatif. Bandung: PT Remaja Rosdakarya.

[19] Moertono, Soemarsaid. Negara \& Kekuasaan di Jawa Abad XVI XIX, 2018

[20] Mulyadi, Dedi, 2016. Republik Bodor - Sebuah Epik Sistem, Cipta Mandiri

[21] Mulyadi, Dedi, 2013.Kang Dedi Menyapa - Kumpulan Pemikiran, Jakarta,Gramedia Printing Group

[22] Mulyadi, Dedi, 2015. Kang Dedi Menyapa II, Jakarta , Gramedia Printing Group

[23] Mulyadi, Dedi, 2017, Kang Dedi Menyapa III, Jakarta, Media Indonesia Publishing

[24] Mulyadi, Dedi, 2015. Spirit Budaya Kang Dedi, Jakarta, Gramedia Printing Group

[25] Mulyadi, Dedi, 2017..Mengayuh Negeri Dengan Cinta, Bandung, Simbiosa Rekatama Media

[26] Mulyadi, Dedi, 2014,.Berguru Pada Kearifan Siliwangi, Penerbit Koekoesan

[27] Mulyana, Deddy, 2011. Komunikasi Efektif, Jakarta, Erlangga

[28] Meniti tangga Purwakarta Istimewa - Rekam Jejak Capaian Pembangunan Kabupaten Purwakarta, 2012, PT Pint of View

[29] Ndraha, Taliziduhu. 2001. Kybernology (Ilmu Pemerintahan baru). Penerbit Rineka Cipta.
[30] Pamudji,S.1995. Kepemimpinan Pemerintahan di Indonesia. Bumi Aksara,Jakarta

[31] Profil Gempungan - Tangga Cinta Purwakaerta Istimewa, Bappeda Kab Purwakarta,Raja Grafindo Persada, Jakarta

[32] Sampurasun, Bidang Pariwisata dan Kebudayaan DISPORAPARBUD kab. Purwakarta

[33] Van Poelje, 1953. Pengantar Umum Ilmu Pemerintahan. NV.Soeroengan,Jakarta.

[34] Vigoda-Gador,Eran 2007. Leadership style, organizational politics, Ana emplooyees performance: An emperical examination of two comperting models,Personal review 30(5): 661683

[35] Yukl.Garry 2010.Leadership in organizations. 7 ed.San Fransisco. CA Pearson

[36] Zaenal, Rivai. 2014. Kepemimpinan \& Perilaku Organisasi. Edisi Keempat: PT Raja Grafindo Persada, Jakarta 